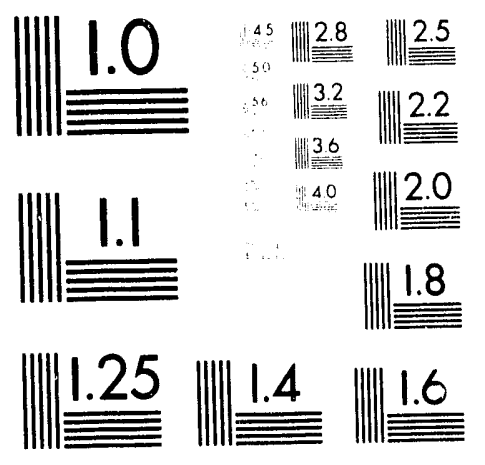



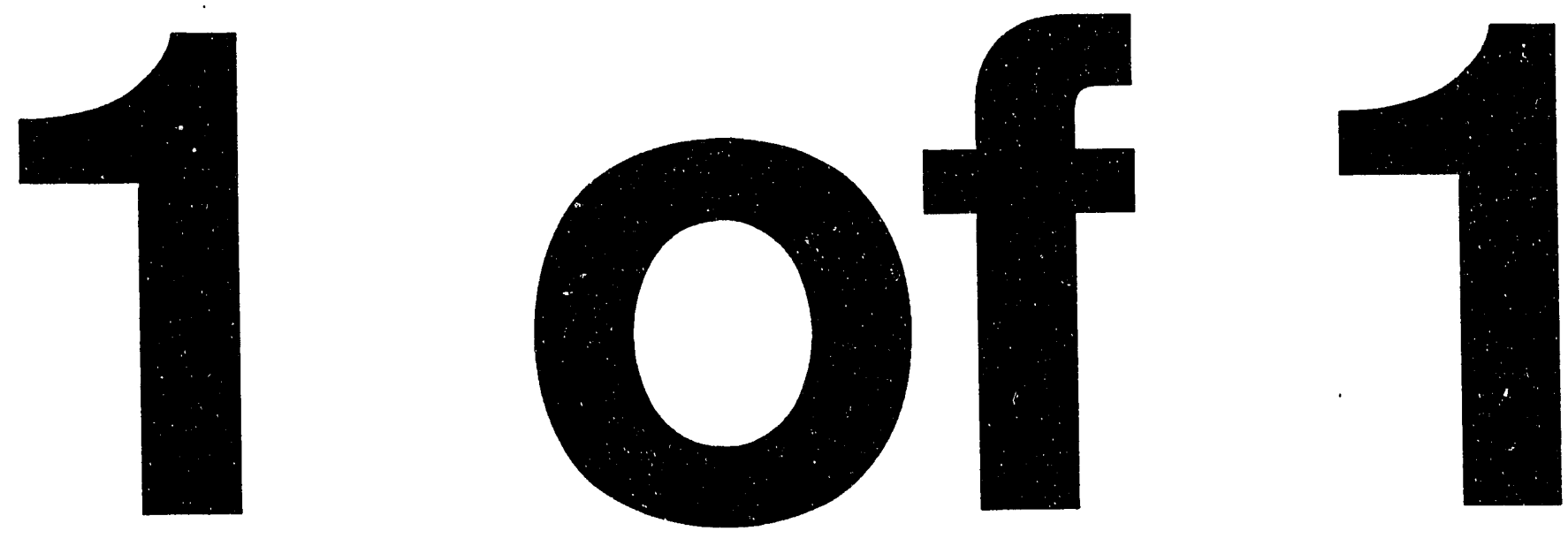


\title{
Surface Wave Attenuation Characteristics at the APS Site
}

\author{
by \\ J. A. Jendrzejczyk, M. W. Wambsganss, and R. K. Smith \\ Materials and Components Technology Division \\ Argonne National Laboratory
}

\section{Introduction}

During operation of the Advanced Photon Source (APS) Facility, there will be many potential sources of vibration that may be transmitted through the ground to the storage ring basemat and experimental hall. These sources include chillers, pumps, blowers and fans. Some may produce amplitudes of sufficient magnitude to adversely affect the stability of the closed orbit of the beam. Where possible, these vibration sources will be monitored as they become operational, to determine their vibrational characteristics, such as amplitude and frequency, and duty cycle.

Vibrations travel through the ground as body [compression (P) and shear (S)] waves and Rayleigh (R) waves, which are surface waves. The amplitudes of these waves decrease with distance from their source as a result of both geometric and material damping. Because the storage ring basemat is "on grade," we are primarily interested in waves on the surface. The $R$-waves, being surface waves, attenuate with distance more slowly than the body waves; for an R-wave, attenuation is proportional to $1 / \sqrt{\mathrm{r}}$, whereas for a body wave at the surface, attenuation is proportional to $1 / \mathrm{r}^{2}$, where $\mathrm{r}$ is the distance from the source [1]. Because R-waves attenuate more slowly, they are of primary interest relative to the isolation of vibration-sensitive facilities such as the APS. Knowledge of th: characterisucs of surface wave attenuation is important, because it will enable estimation of the response of vibration-sensitive components that are some distance from a vibration source.

Measurement of surface wave attenuation requires a vibration source that is capable of producing a ground displacement level considerably greater than that of the ambient background. A pile driver that was used to drive steel pilings at the APS vehicle tunnel provided such a source. 


\section{Objective}

To measure and characterize the attenuation of surface waves at the APS site.

\section{Technical Approach}

A linear string of seven accelerometers, extending from the vibration source (pile driver at the APS vehicle tunnel) and nominally directed toward the monument at the center of the storage ring, were positioned as shown in Fig. 1. The purpose of the accelerometer string was to generate a data base for calculating the surface wave attenuation characteristics of the soil. Each accelerometer was vertically oriented and mounted on a 24 -in.-long steel stake driven into the clay soil. The accelerometer signals were double-integrated to obtain displacement, which were recorded on an FM analog tape recorder. Amplitude and frequency information was calculated with a fast Fourier transform (FFT) analyzer.

As noted above, attenuation is a result of material damping as well as geometric damping, which is proportional to $1 / \sqrt{\mathrm{r}}$. An expression for calculating $\mathrm{R}$-wave attenuation by both types of damping can be written as [1]

$$
w=w_{1} \sqrt{\frac{r_{1}}{r}} e^{-\alpha\left(r-r_{1}\right)}
$$

where $w$ and $w_{1}$ are the vertical amplitudes of the $R$-wave, corresponding to distances $r$ and $r_{1}$, respectively, from the source (the subscript 1 defines the reference location), and $\alpha$ is the coefficient of attenuation accounting for sitespecific-material damping ( $\alpha$ has the dimensions of $1 /$ distance). The coefficient of attenuation is frequency dependent, generally increasing with frequency.

\section{Measurements and Results}

\section{Date and conditions}

Measurements were made on April 8, 1992, from approximately 11:00 to 11:30 a.m. Construction activity was normal during the period of data recording. The soil, which consisted primarily of compacted clay, was fairly wet, with some areas of standing water. Air temperature averaged approximately $60^{\circ} \mathrm{F}$. 


\section{Vibration Source Characteristics}

A typical displacement-time trace of the vertical soil response to pile driver vibration at Accelerometer 2 is shown in Fig. 2a. A time expansion, corresponding to the small rectangle at the left end of the trace of Fig. 2a, is displayed in Fig. 2b. Spectral content of the acceleration-time trace of Fig. 2 is given in Fig. 3, where it can be seen to consist of a series of harmonics of the pile driver impact rate. The low-frequency cutoff, governed by the frequency response of the accelerometer/integrator system (typically $<4 \mathrm{~Hz}$ ), does not permit observation of the fundamental and its second harmonic. The harmonic frequencies observed, including estimates of the fundamental and second harmonic, are given in Table 1. Typically, one would expect all harmonics to be present in a spectral decomposition of a short rectangular pulse, which is basically what is produced when the hammer of the pile driver strikes the steel beam, and this is what was observed.

\section{R-Wave Velocity}

Velocity of the R-wave can be calculated by measuring the propagation time of the large pulse, shown in Fig. 2, along the accelerometer string. With Accelerometer 1 as a reference, the transit times and corresponding wave speeds obtained from the remaining six accelerometer locations are given in Table 2; the average calculated wave speed is $779 \mathrm{ft} / \mathrm{s}$. The measured site shear wave velocity varied from 718 to $1026 \mathrm{ft} / \mathrm{s}$ at a depth of $5 \mathrm{ft}$ [2]. Because the shear wave typically travels at $\approx 1.1$ times the speed of the $R$-wave [1], the measured value is equivalent to a shear wave velocity of $857 \mathrm{ft} / \mathrm{s}$, which falls in the middle of the measured shear wave velocity range.

\section{P-Wave Velocity}

Calculaiion of the compression, or P-wave velocity is the same as that for the R-wave, except that the smaller first-arrival pulse (see Fig. 2) is used; the calculated transit times and corresponding speeds for the $\mathrm{P}$-wave are given in Table 3 . From the location of the fifth accelerometer on, the wave was sufficiently attenuated in amplitude as to be indistinguishable from background noise. The averaged P-wave speed from the three measurements was $1776 \mathrm{ft} / \mathrm{s}$.

\section{Surface Wave Attenuation}

The measured (average of two pulses) ground displacements in peak $\mu \mathrm{m}$, are given in Table 4. Coefficients of attenuation, in $\mathrm{ft}^{-1}$, were calculated from Eq. 1 
the location of the first accelerometer as the reference. The average of the six values is $\approx 0.003$. In Fig. 4 , the measured displacements as a function of distance from the source (pile driver) are compared with displacements calculated from Eq. 1, with $\alpha$ equal to 0.003 and the location of the first accelerometer as the reference. Calculated displacements, resulting from geometric damping alone are also shown. The results are in good qualitative agreement with results from similar studies by other investigators, reported in Ref. 1 .

\section{Frequency Dependence}

As mentioned previously, the coefficient of attenuation is a function of many parameters, such as soil type, moisture content, underlying geologic conditions, and amplitude and frequency of the source vibration. The spectral content of the resulting vertical ground displacement, shown in Fig. 3, has harmonics extending to frequencies $>40 \mathrm{~Hz}$. Coefficients of attenuation corresponding to the individual harmonics can be calculated to obtain an approximation of the effect of frequency. Because the results for frequencies greater than $22-\mathrm{Hz}$ are less consistent on the more distant accelerometers, only harmonics up to the 14 th harmonic $(21.27 \mathrm{~Hz})$ were used. The calculated coefficients of attenuation, as a function of frequency, are given in Fig. 5. Although there is scatter, a trend can be observed and a third-order polynomial curve fit (represented by the dashed line on Fig. 5) was generated to quantify this trend. The equation of the curve is

$$
\alpha=0.0334-(0.000412) f+\left(1.93 \times 10^{-5}\right) \mathrm{f}^{2}+\left(3.75 \times 10^{-7}\right) \mathrm{f}^{3},
$$

which gives an approximation of the effect of source frequency (f) on the coefficient of attenuation.

\section{Summary and Conclusions}

This study provides a measure of the attenuation of surface waves in the ground by the combination of geometric and material damping. An average coefficient of attenuation of 0.003 was derived from measured responses to vibrations provided by a pile driver. When energy transmission is predominantly through the ground, the coefficient allows the use of the attenuation equation, Eq. 1 , to predict ground motion at a given distance from a known vibration source. In general, results of previous vibration studies at the APS site, e.g., Ref. 3, have shown that a foundation or basemat will follow ground motion, especially in the vertical direction. It follows that knowledge of the coefficient of attenuation will allow prediction of structural responses of vibration-sensitive components to 
distant vibration sources (those within or adjacent to the site but removed from the vibration-sensitive component).

The study clearly demonstrates the importance of using distance as an effective means of isolation when designing vibration-sensitive facilities. However, it should be noted that transmission of vibrations through the ground by surface waves is only one of several possible energy transmission paths. Because the APS facility is structurally very complex, there will be many different vibration transmission paths, such as large buried pipes and electrical conduits. These will have to be considered and evaluated as well.

\section{References}

1. Richart, F. E., Jr., Hall, J. R., Jr., and Woods, R. D., Vibrations of Soils and Foundations, pp. 244-247, Prentice-Hall, Inc., Englewood Cliffs, NJ (1970).

2. Draft Report - Subsurface Exploration and Geotechnical Engineering Evaluation, Vol. II, STS Consultants, Ltd., Northbrook, IL (1988).

3. Jendrzejczyk, J. A., Wambsganss, M. W., and Smith, R. K., Vibration Response of Linac Floor Slab to Ambient Ground Motion, ANL/APS/IN/VIB/92-1 (Nov. 1991). 
Table 1. Frequency content of ground displacement produced by pile driver

\begin{tabular}{cc}
\hline & $\begin{array}{c}\text { Frequency } \\
\text { Harmonic }\end{array}$ \\
\hline 1 & 1.52 \\
2 & 3.04 \\
3 & 4.56 \\
4 & 6.08 \\
5 & 7.60 \\
6 & 9.12 \\
7 & 10.64 \\
8 & 12.16 \\
9 & 13.68 \\
10 & 15.20 \\
11 & 16.71 \\
12 & 18.23 \\
13 & 19.75 \\
14 & 21.27 \\
15 & 22.79 \\
\hline
\end{tabular}


Table 2. Measured R-wave velocity

\begin{tabular}{ccc}
\hline $\begin{array}{c}\text { Distance from pile } \\
\text { driver, } \mathrm{ft}\end{array}$ & $\begin{array}{c}\text { Transit time, } \\
\mathrm{s}\end{array}$ & $\begin{array}{c}\text { R-wave velocity, } \\
\mathrm{ft} / \mathrm{s}^{\mathrm{a}}\end{array}$ \\
\hline 180 & Reference & \\
270 & 0.137 & 657 \\
360 & 0.225 & 800 \\
410 & 0.297 & 774 \\
460 & 0.337 & 831 \\
510 & 0.421 & 784 \\
560 & 0.458 & 830 \\
\hline
\end{tabular}

aAverage $\mathrm{R}$-wave velocity was $779 \mathrm{ft} / \mathrm{s}$. 
Table 3. Measured P-wave velocity

\begin{tabular}{ccc}
\hline $\begin{array}{c}\text { Distance from pile } \\
\text { driver, } \mathrm{ft}\end{array}$ & $\begin{array}{c}\text { Transit time, } \\
\mathrm{s}\end{array}$ & $\begin{array}{c}\text { P-wave velocity, } \\
\mathrm{ft} / \mathrm{s}^{\mathrm{a}}\end{array}$ \\
\hline 180 & Reference & \\
270 & 0.0518 & 1737 \\
360 & 0.0993 & 1813 \\
410 & 0.1293 & 1779 \\
\hline
\end{tabular}

aAverage P-wave velocity was $1776 \mathrm{ft} / \mathrm{s}$. 
Table 4. Calculated coefficient of attenuation, $\alpha$, as a function of distance from pile driver

\begin{tabular}{cccc}
\hline $\begin{array}{c}\text { Accelerometer } \\
\text { number }\end{array}$ & $\begin{array}{c}\text { Distance from } \\
\text { pile driver, } \\
\mathrm{ft}\end{array}$ & $\begin{array}{c}\text { Ground } \\
\text { displacement, } \\
\text { peak } \mu \mathrm{m}\end{array}$ & $\begin{array}{c}\text { Coefficient of } \\
\text { attenuation, } \\
\mathrm{ft}^{-1} \mathbf{1}^{\mathbf{a}}\end{array}$ \\
\hline 1 & 180 & 1.79 & \\
2 & 270 & 1.11 & 0.00307 \\
3 & 360 & 0.645 & 0.00375 \\
4 & 410 & 0.627 & 0.00278 \\
5 & 460 & 0.466 & 0.00313 \\
6 & 510 & 0.519 & 0.00217 \\
7 & 560 & 0.340 & 0.00288 \\
\hline
\end{tabular}

aAverage coefficient of attenuation was 0.00296 . 


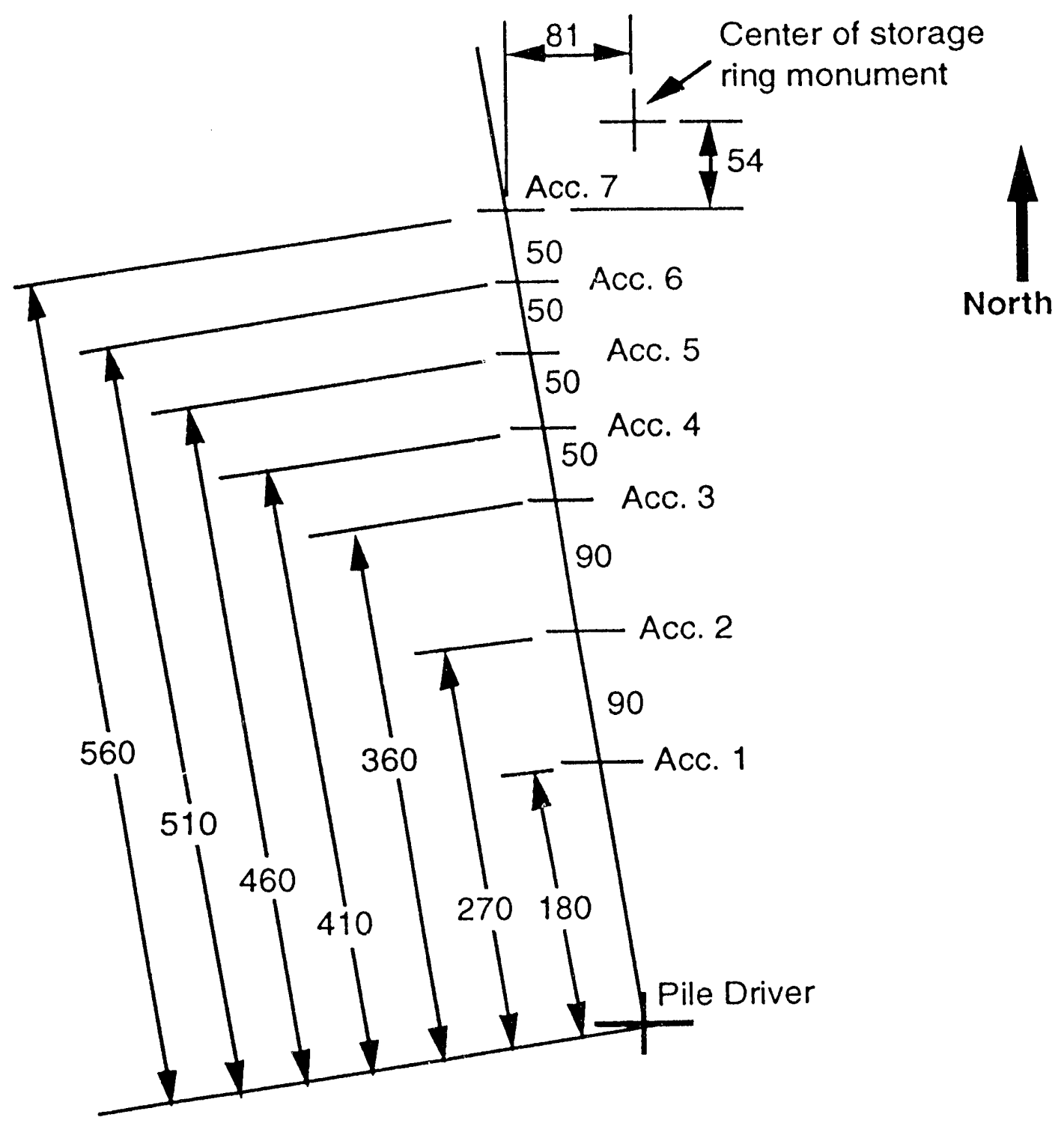

Note: All dimensions in feet

Fig. 1. Schematic representation of string of accelerometers used to measure surface wave attenuation 

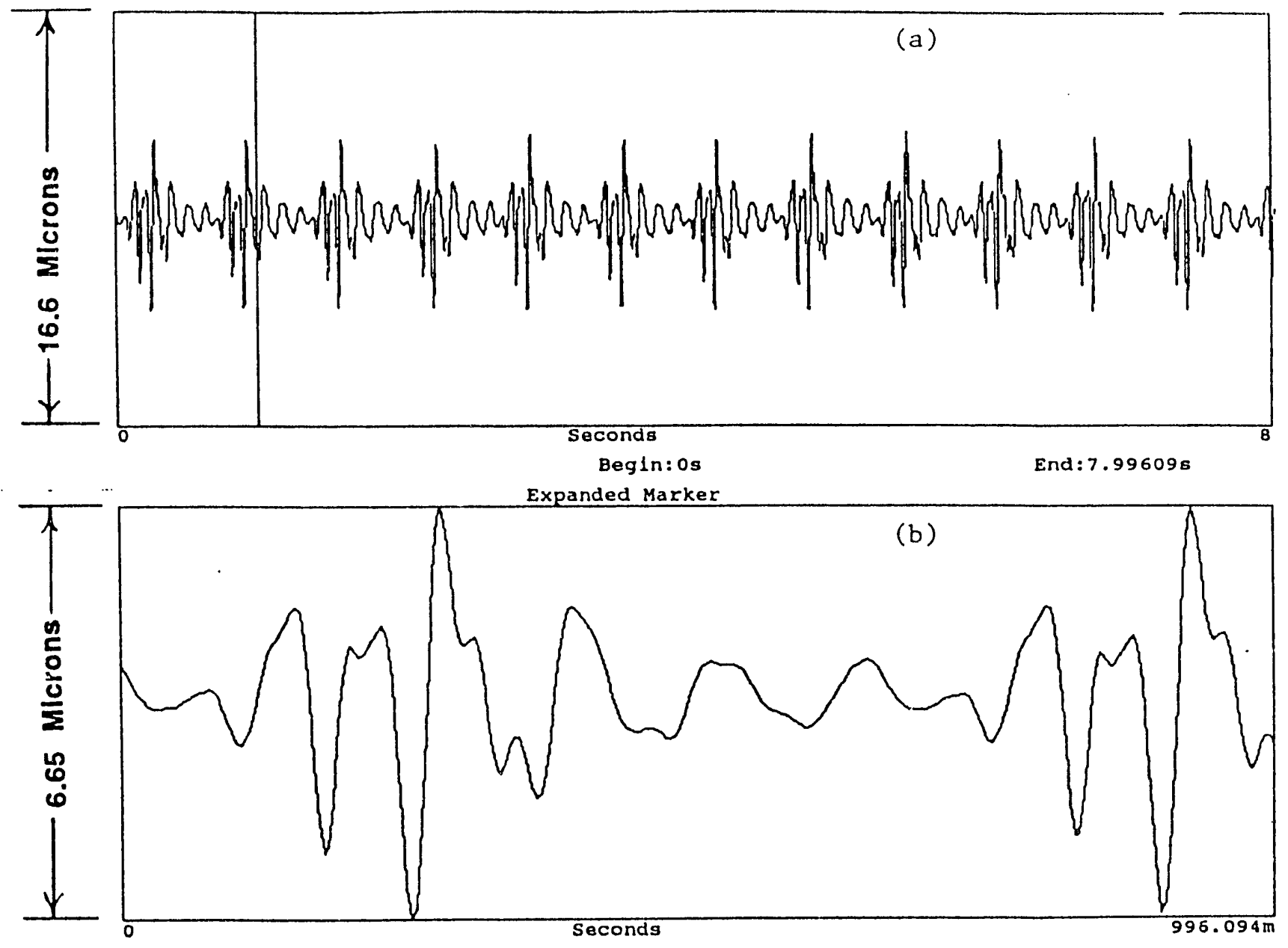

Fig. 2. Vertical ground displacement (a) at Accelerometer 2 due to pile driving and (b) time expansion of left-hand rectangular area of (a) 


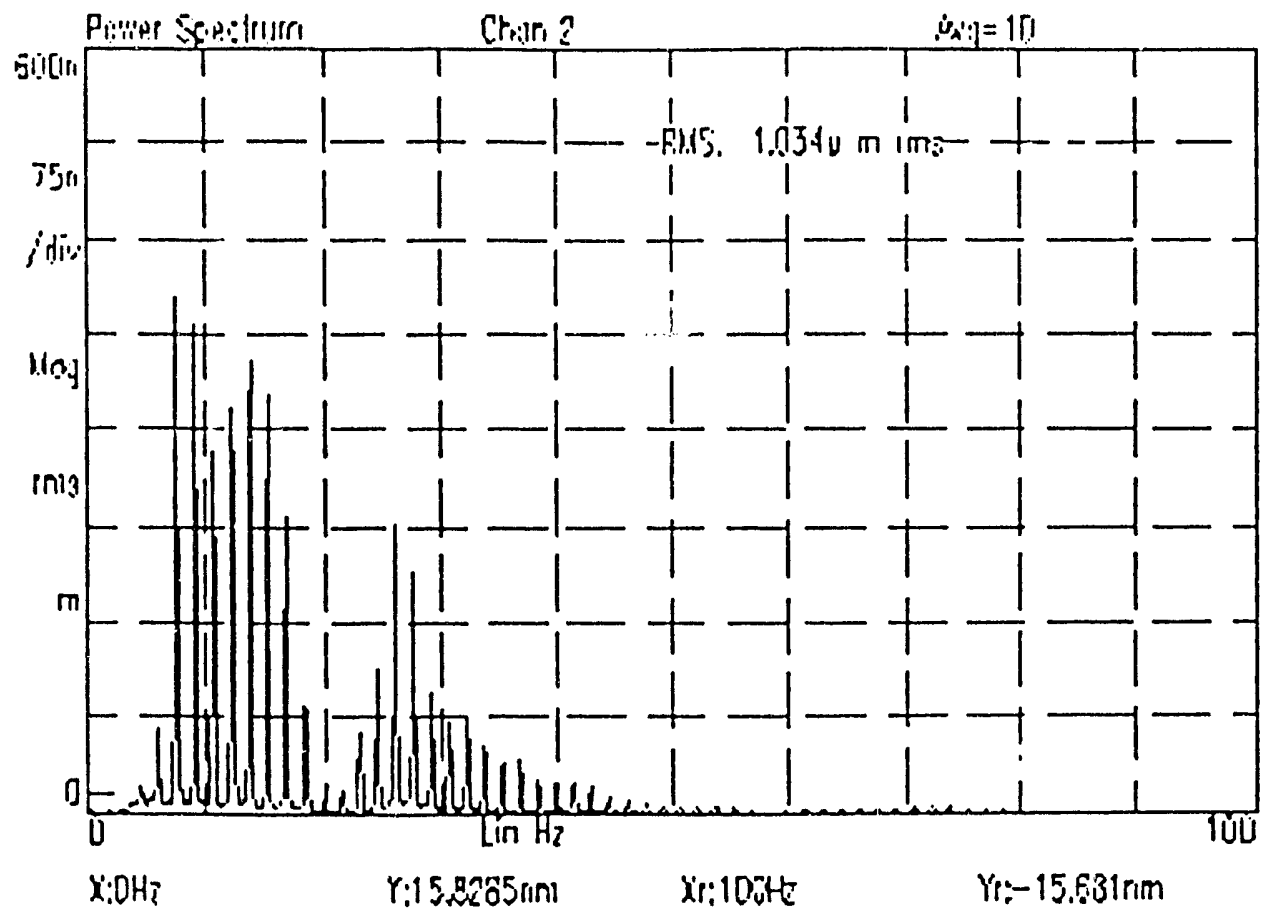

Fig. 3. Spectral content of vertical ground displacement at Accelerometer 2 due to pile driving 


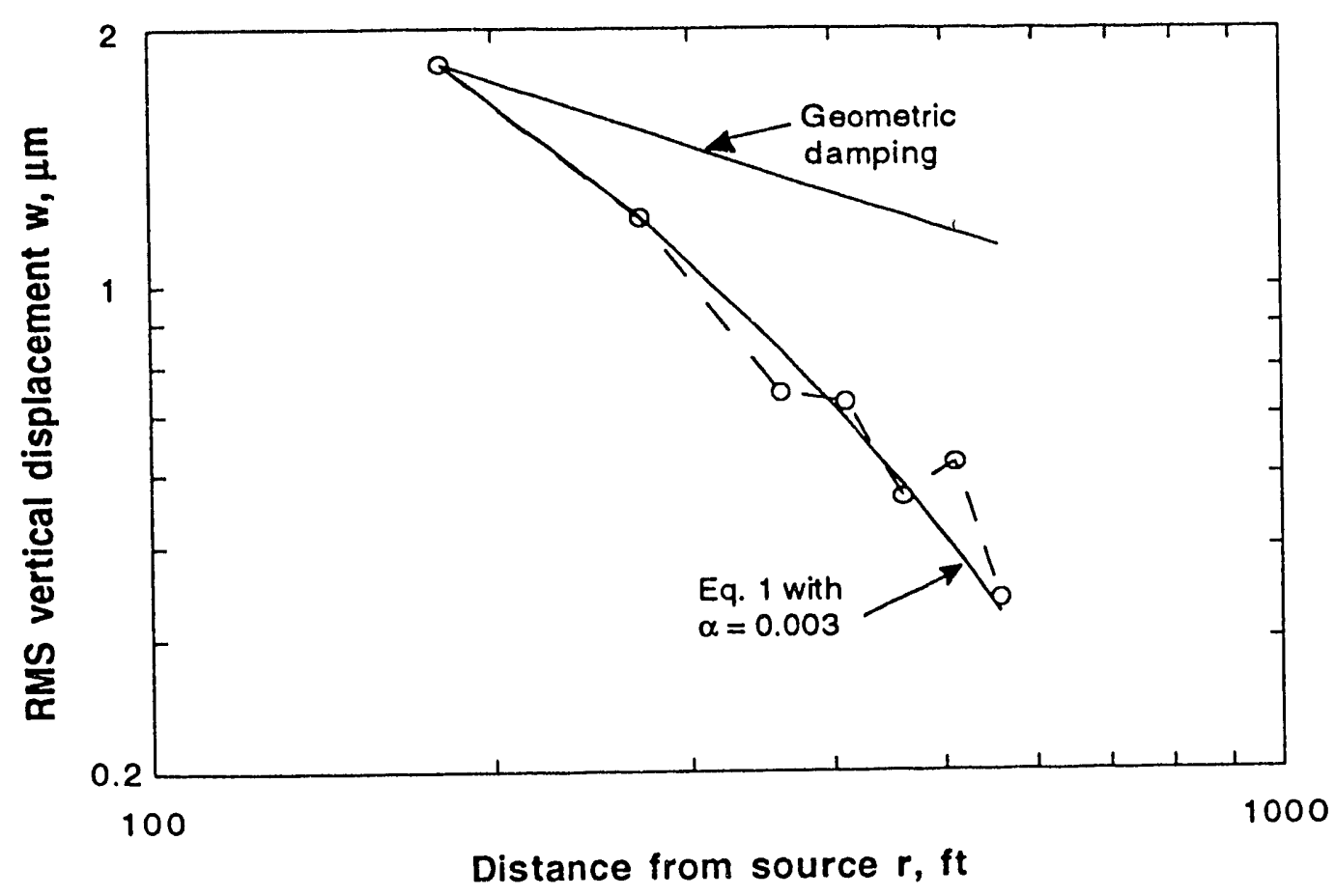

Fig. 4. Comparison of measured ground displacement as a function of distance from pile driver (- $\left.-0_{-}-\right)$with curves for geometric damping and Eq. 1 with $\alpha=0.003$ 


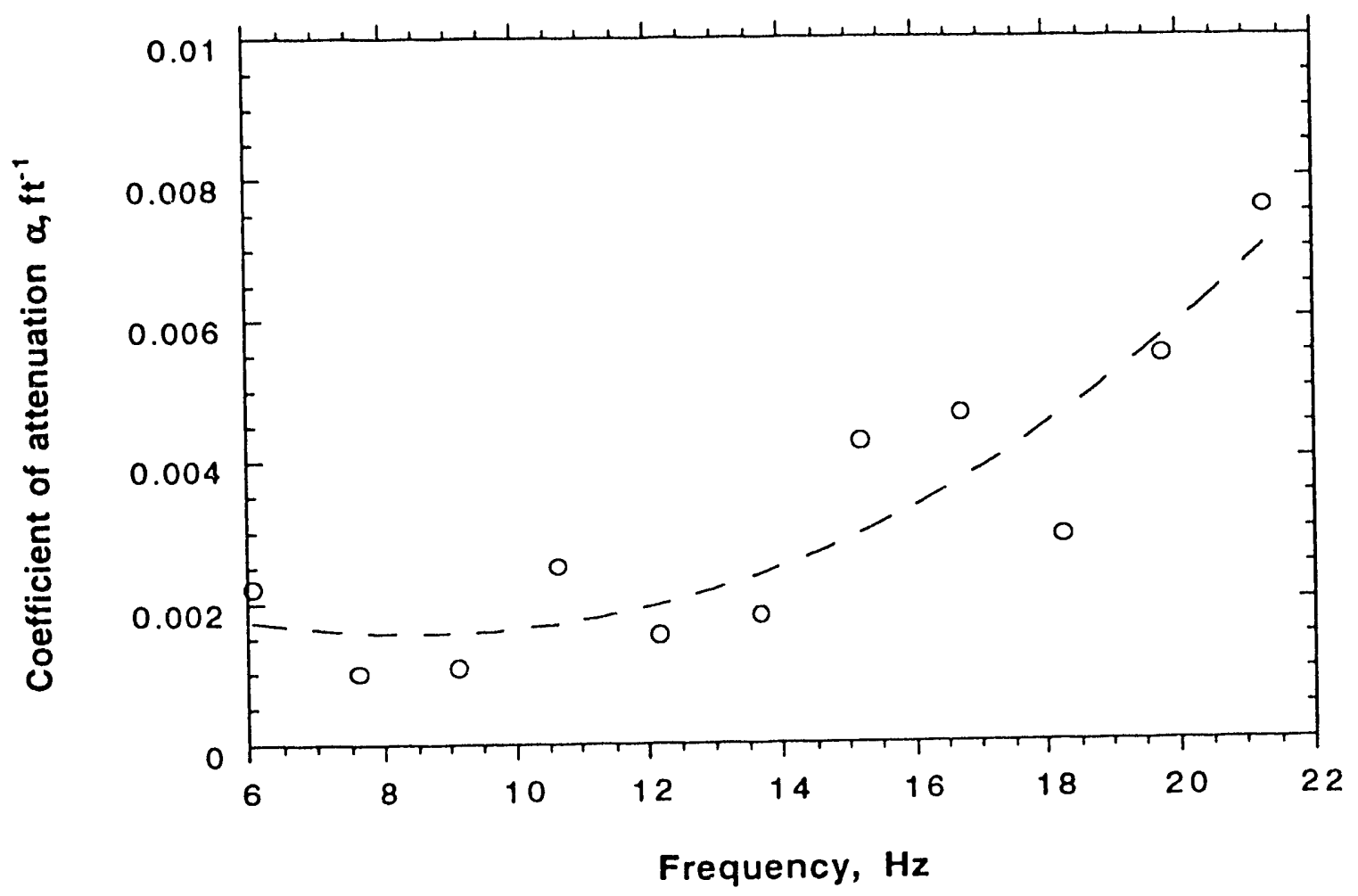

Fig. 5. Calculated coefficients of attenuation as a function of frequency 

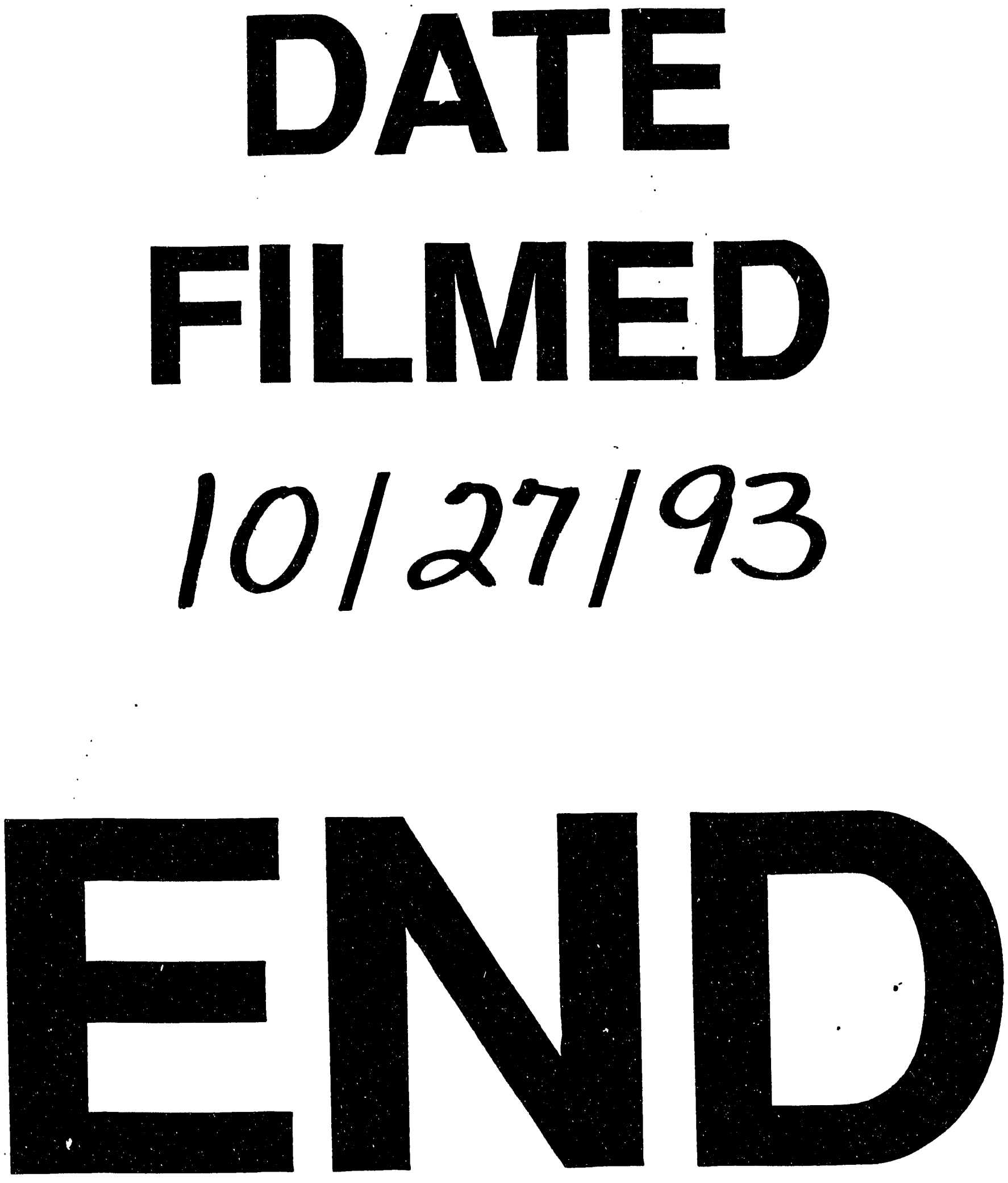


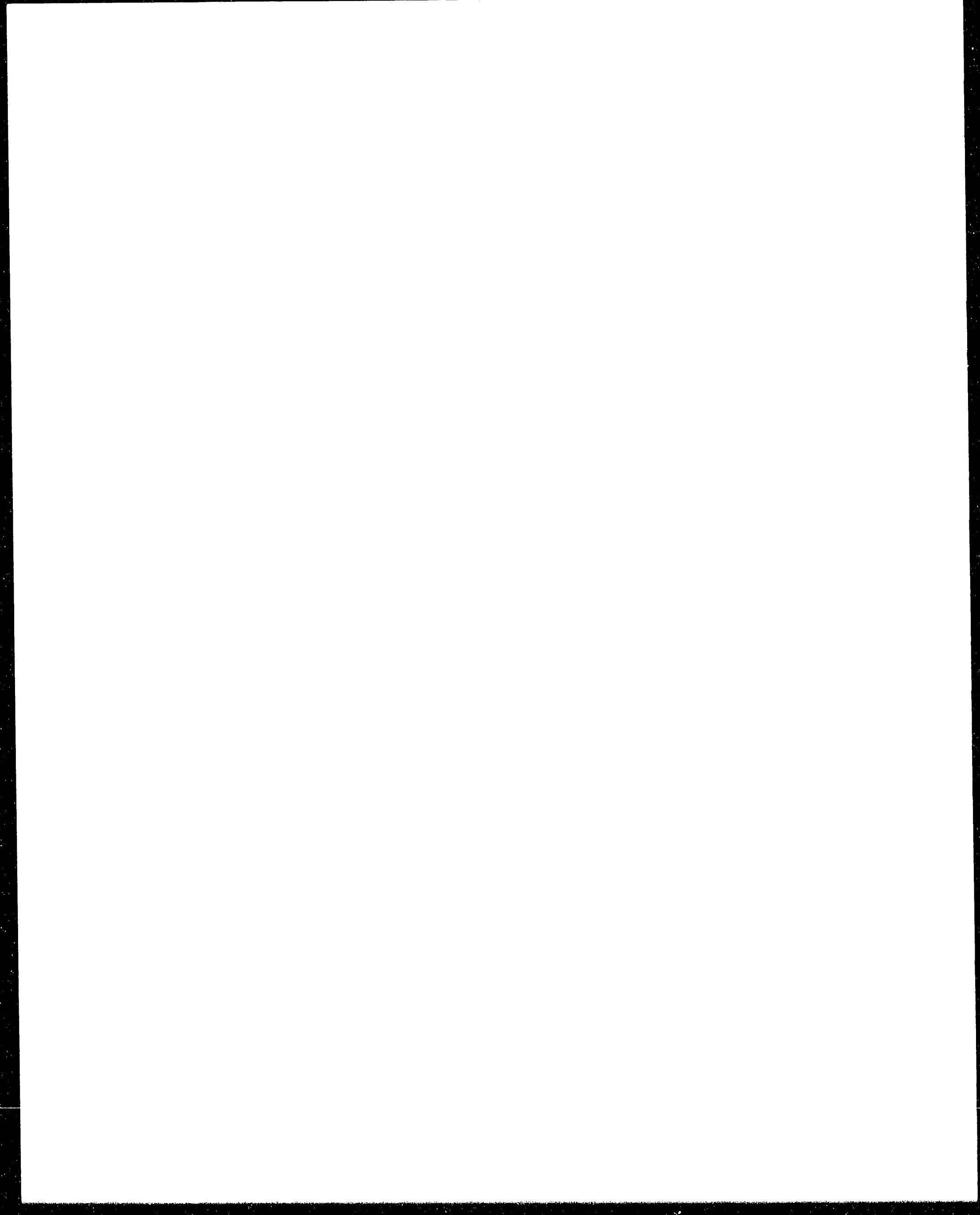

